OPEN ACCESS

Edited by: Umberto Volpe, Marche Polytechnic University, Italy

Reviewed by: Devashish Konar, Mental Health Care Centre, India Thomas Wenzel, Medizinische Universität Wien, Austria

*Correspondence: Antonio G. Lentoor dr.lentoor.antonio@gmail.com

Specialty section: This article was submitted to Public Mental Health, a section of the journal Frontiers in Psychiatry

Received: 03 February 2021 Accepted: 12 May 2021 Published: 21 June 2021

Citation:

Lentoor AG and Maepa MP (2021) Psychosocial Aspects During the First Wave of COVID-19 Infection in South Africa. Front. Psychiatry 12:663758. doi: 10.3389/fpsyt.2021.663758

\section{Psychosocial Aspects During the First Wave of COVID-19 Infection in South Africa}

\author{
Antonio G. Lentoor* and Mokoena Patronella Maepa \\ Department of Clinical Psychology, School of Medicine, Sefako Makgatho Health Sciences University, Pretoria, South Africa
}

Background: In South Africa, as in many countries, the nationwide spread of COVID-19 caused a public health emergency that resulted in the government implementing necessary restrictive measures such as the nationwide lockdown as a way of containing the pandemic. Such restrictive measure, while necessary, can disrupt many aspects of people's lives resulting in unprecedented psychosocial distress.

Aim: The present study aims to describe the psychosocial health and situational factors associated with the novel coronavirus (COVID-19) in South Africa during the first wave of infection.

Methods: This cross-sectional survey, recruited a total of 203 participants through convenience sampling via online platforms - WhatsApp, Facebook, emails, etc. - during COVID-19 lockdown in the country. Through the snowball technique, participants from across South Africa completed the online survey that assessed socio-demographic information, risk perception, history of mental health, COVID-19-related stress, and fears during the lockdown (first wave).

Results: The majority of the participants who completed the survey were young, Black African, and female. Participants reported feelings of stress and anxiety (61.2\%); stress about finances (39.5\%); and feelings of sadness, anger, and/or frustration (31.6\%) during the lockdown. Females compared to males were more likely to perceive COVID-19 as a risk to their household, $X_{(20)}^{2}=45,844, p<0.001$ and community, $X_{(20)}^{2}=40,047$, $p=0.005$. COVID-19 differentially impacted the mental health of participants with and without mental health diagnosis, $X_{(4)}^{2}=16.596, p=0.002$. Participants with a prior mental health diagnosis reported significant extra stress during lockdown $(p<0.05)$.

Conclusion: The findings may be of significance to assist in the development of targeted psychosocial interventions to help people during and after the pandemic.

Keywords: COVID-19, psychosocial, lockdown 2020, mental health, stress, threat, anxiety, depression

\section{INTRODUCTION}

In January 2020, the World Health Organization (WHO) declared the outbreak of SARS-CoV-2, the virus that causes COVID-19, a public health emergency that raised an international concern (1). The disease has its origin in Wuhan, a Chinese city where it first appeared in December 2019 (2). By 2020 , the international concern was heightened due to the rapid domestic and international 
spread of the virus. On January 30, 2020, the WHO declared the coronavirus a public health emergency of international concern (3). By end of February 2020, several countries had confirmed reported cases of the COVID-19 virus. On March 11, 2020, WHO declared the novel coronavirus disease a pandemic (4). Soon after, the Minister of Health of South Africa confirmed 13 positive cases of coronavirus as reported by the National Institute for Communicable Diseases, and by April 14, 2020, a total number of confirmed laboratory cases of COVID-19 of 2,272 with 27 reported COVID-19-related fatalities and 410 recoveries were reported (5).

It goes without saying that the first-ever global outbreak of the COVID-19 has negatively impacted the general population at large, with a considerable toll not only on healthcare needs but also various spheres of the life of individuals (6). A large proportion of the South African population has diverse and pre-existing vulnerable life situations, such as socioeconomic and health disparities. In line with the international response to contain the spread of COVID-19, South Africa went on a nationwide "hard" lockdown in March 2020, which inevitably singled crises and the general distress among the population. It is understood that a public health crisis of this nature cannot go without inflicting anxiety and fear throughout the population, resulting in a wide range of psychological health and social problems $(7,8)$. While lockdown is a necessity in situations such as this, it has caused distress, for example, the quarantine added stress, pay-cuts, unemployment, work and/or income uncertainty, fear, etc. Negative psychological impacts and unprecedented economic crises associated with the lockdown were reported in studies conducted outside of South Africa. For example, increased stress and anxiety related to COVID vulnerability, financial-related stress, and increased unemployment rates due to the loss of jobs after lockdown were reported in several countries (9). Previous findings showed that disruptions to people's work and lives were associated with negative effects on physical and mental health (10). While everyone is affected by the pandemic, povertyridden families, and communities are the hardest hit by the economic repercussions of the pandemic (11). Therefore, in this novel situation, social stress among individuals, families, and communities is unavoidable, and the risk for mental health problems is inevitable. The present study aims to describe the psychosocial health and situational factors associated with the novel coronavirus (COVID-19) in South Africa during the first wave of infection.

\section{MATERIALS AND METHODS}

\section{Research Design}

In this prospective population-based cross-sectional study, individuals who were living in South Africa at the start of COVID-19, aged 18 years and older, and were able to provide informed consent, were eligible to participate in the study.

\section{Sample Size}

The sample size was calculated with a 95\% confidence level with a $5 \%$ margin of error and $50 \%$ response distribution, which was considered acceptable. A minimum of at least 300 people to complete the online survey was required. In terms of the numbers selected above, the sample size $n$ and margin of error $E$ are given by

$$
\begin{array}{r}
x=Z\left({ }^{c} / 100\right)^{2} r(100-r) n={ }^{N x} /\left[(\mathrm{N}-1) \mathrm{E}^{2}+\mathrm{x}\right] \\
E=S q r t\left[{ }^{(\mathrm{N}-\mathrm{n}) \mathrm{x}} / \mathrm{n}(\mathrm{N}-1)\right],
\end{array}
$$

where $N$ is the population size, $r$ is the fraction of responses that you are interested in, and $Z(c / 100)$ is the critical value for the confidence level $c$.

\section{Study Measures}

The online survey consisting of questions that asked about socio-demographic, psychological, and health status prior to and during COVID-19 were constructed.

\section{Sociodemographics}

The participants' age group, gender, ethnicity, level of education, marital status, province of living, and employment status were collected.

\section{Mental Health}

Participants were asked whether they had ever been diagnosed with a mental health problem such as depression and anxiety (Yes, No), whether they are currently being treated for a mental health problem (Yes, No), and what current treatment they are receiving (Psychiatric medication only, Psychotherapy only, Combined psychiatric medication and psychotherapy, Other).

\section{COVID-19-Related Stress}

Participants were asked whether they were struggling with lockdown [feelings of stress and anxious (anxiety), sadness, anger, and/or frustration (depressed); problems in family relationships; problems in romantic relationships; stress about finances; thoughts and/or feelings of suicide; or increased use of alcohol/cigarettes/drugs].

\section{Seeking Mental Healthcare During the Lockdown}

Participants were asked whether they sought mental healthcare for COVID-19-lockdown-related difficulties (Yes, No).

\section{COVID-19 Threat and Fear}

Participants were assessed how much a threat COVID-19 was to their country, city, community, and household (Yes, No); if they were afraid of contracting COVID-19 (Yes, No); if they worried for their family or friends contracting COVID-19 (Yes, No).

\section{Procedure and Data Collection}

In line with the South African government's recommendation of social distancing and national lockdown to minimize faceto-face contact, the use of the electronic platform, an online survey was deemed the most feasible method for the collection of data. All participants were invited to complete an online survey that was distributed on various social media platforms, including Facebook, Twitter, university websites, WhatsApp, forums, etc. Using a snowball sampling strategy, an anonymous online questionnaire was distributed for data collection during 
the period of March 5, 2020 to November 31, 2020, the first wave of infection.

\section{Ethical Consideration}

Ethical approval was received from Sefako Makgatho University Research Ethics Committee (SMUREC/M/73/2020: IR), and the research was carried out in accordance with the Declaration of Helsinki of the World Medical Association, and participants gave informed written consent.

\section{Statistical Analysis}

Descriptive statistics were used to compile socio-demographic and health profiles of the study sample and were expressed in mean $(M)$, standard deviations $(S D)$, and frequency data. Inferential statistics such chi-square test (nominal data) for differences in socio-demographic, psychosocial, and health factors were conducted in the study. All analyses were conducted using IBM SPSS Statistics version 20 (IBM Corporation, Armonk, NY, USA.), with a level of significance set at 0.05, two-tailed.

\section{RESULTS}

A total of 306 people age 18 and older consented and completed the online survey. Basic socio-demographic characteristics were presented in Table 1. Of the participants, $45.8 \%$ were Black African, 15.4\% White, 6.9\% Indian/Asian, and 3.3\% Colored. The majority of the participants who completed the survey were female $(71.2 \%)$ compared to $28 \%$ male and were married (49\%). The majority of the participants who completed the online survey lived in Gauteng (48.4\%) followed by Limpopo province $(12.7 \%)$ during the lockdown of the first wave of the pandemic.

Of all the participants, $61.2 \%$ reported feelings of stress and anxiety, while $39.5 \%$ reported stress about finances, and $31.6 \%$ reported feelings of sadness, anger, and/or frustration since the beginning and/or during the lockdown. The percentage of all three indicators was comparatively higher among women than men. In comparison, the higher age group (participants 45 years and older) reported higher percentages of stress, anxiety, and depressive symptoms than the younger age group (participants $18-44$ years), but the differences were not statistically significant $(p=0.666)$.

Of all the participants, only $32 \%$ reported seeking out mental healthcare for COVID-19-related challenges during the lockdown (Figure 1). A significantly higher percentage of females compared to males were seeking out mental healthcare specifically related to challenges experienced during COVID19 lockdown (23 vs. $9 \%, p<0.001$ ) (Table 2). The majority of the participants considered COVID-19 a serious threat either to communities (76.6\%) and households (80.9\%). Females compared to males were more likely to perceive COVID-19 as a risk to their household, $X_{(20)}^{2}=45,844, p<0.001$ and community, $X_{(20)}^{2}=40,047, p=0.005$.

Of the participants who completed the survey, over $70 \%$ were still required to continue working during the lockdown. Moreover, over $60 \%$ reported their work to be stressful, while over $40 \%$ reported extra stress at work during the COVID19 , and close to $34 \%$ believed that their work was increasing
TABLE 1 | Sociodemographic characteristics of all the participants in the study ( $N$ $=306$ ).

\begin{tabular}{|c|c|c|c|c|c|c|}
\hline \multirow[t]{2}{*}{ Characteristics } & \multicolumn{2}{|c|}{ All participants } & \multicolumn{2}{|c|}{ Female } & \multicolumn{2}{|c|}{ Male } \\
\hline & $n$ & (\%) & $n$ & (\%) & $n$ & (\%) \\
\hline \multicolumn{7}{|l|}{ Age (years) } \\
\hline $18-29$ & 84 & 27.5 & 71 & 23.2 & 13 & 4.2 \\
\hline 30-44 & 138 & 45.1 & 90 & 29.4 & 48 & 15.7 \\
\hline $45-54$ & 47 & 15.4 & 33 & 10.8 & 14 & 4.6 \\
\hline $55-64$ & 29 & 9.5 & 20 & 6,5 & 9 & 2.9 \\
\hline $65+$ & 8 & 2.5 & 4 & 1.3 & 4 & 1.3 \\
\hline \multicolumn{7}{|l|}{ Race/Ethnicity } \\
\hline Black African & 140 & 45.8 & 96 & 31.4 & 44 & 14.4 \\
\hline White & 47 & 15.4 & 37 & 12.1 & 10 & 3.3 \\
\hline Colored & 10 & 3,3 & 8 & 2.6 & 2 & 0,7 \\
\hline Indian/Asian & 21 & 6.9 & 13 & 4.2 & 8 & 2.6 \\
\hline \multicolumn{7}{|l|}{ Relationship status } \\
\hline Dating & 66 & 21.6 & 36 & 11.8 & 30 & 9.8 \\
\hline Married & 150 & 49.0 & 111 & 36.3 & 39 & 12.7 \\
\hline Divorced & 10 & 3.3 & 9 & 2.9 & 1 & 0.3 \\
\hline Single & 100 & 32.7 & 77 & 25.2 & 23 & 7.5 \\
\hline \multicolumn{7}{|l|}{ Highest level of education } \\
\hline High school & 22 & 7.2 & 14 & 4.6 & 8 & 2.6 \\
\hline Bachelor's degree & 86 & 28.1 & 58 & 19.0 & 28 & 9.2 \\
\hline Post-graduate degree & 197 & 64.4 & 146 & 47.7 & 51 & 16.7 \\
\hline \multicolumn{7}{|l|}{ Occupation status } \\
\hline Employed & 226 & 73.9 & 160 & 52.3 & 66 & 21.6 \\
\hline Unemployed & 27 & 8.8 & 21 & 6.9 & 6 & 2.0 \\
\hline Other (student) & 45 & 14.7 & 35 & 11.4 & 10 & 3.3 \\
\hline \multicolumn{7}{|l|}{ Province } \\
\hline Eastern Cape & 18 & 5.9 & 12 & 3.9 & 6 & 2.0 \\
\hline Free State & 7 & 2.3 & 4 & 1.3 & 3 & 1.0 \\
\hline Gauteng & 148 & 48.4 & 106 & 34.6 & 42 & 13.7 \\
\hline KwaZulu Natal & 26 & 8.5 & 21 & 6.9 & 5 & 1.6 \\
\hline Limpopo & 39 & 12.7 & 31 & 10.1 & 8 & 2.6 \\
\hline Mpumalanga & 11 & 3.6 & 5 & 1.6 & 6 & 2.0 \\
\hline North West & 17 & 5.6 & 9 & 2.9 & 8 & 2.6 \\
\hline Northern Cape & 4 & 1.3 & 2 & 0.7 & 2 & 0.7 \\
\hline Western Cape & 35 & 11.4 & 28 & 9.2 & 7 & 2.3 \\
\hline \multicolumn{7}{|c|}{ Required to work in lockdown } \\
\hline Yes & 215 & 70.3 & 149 & 48.7 & 66 & 21.6 \\
\hline No & 70 & 22.9 & 53 & 17.3 & 17 & 5.6 \\
\hline \multicolumn{7}{|l|}{ History of mental illness } \\
\hline Diagnosed with mental illness & 53 & 16.1 & 40 & 17.2 & 11 & 11.9 \\
\hline
\end{tabular}

their vulnerability for COVID-19. Fear of contracting COVID19 through the job (or work) was reported by $47.5 \%$ of the participants (Figure 1), but they felt that they had little control over it.

Of the overall sample, a total of 53 (16.1\%) of the participants had a mental health condition that was diagnosed prior to COVID-19, and $10.4 \%$ reported receiving psychiatric care. Psychotropic medication only (5.5\%), psychotherapy only (4.8\%), or combined psychiatric and psychotherapy $(0.9 \%)$ 


\section{Potentential impact of COVID-19 and gender}

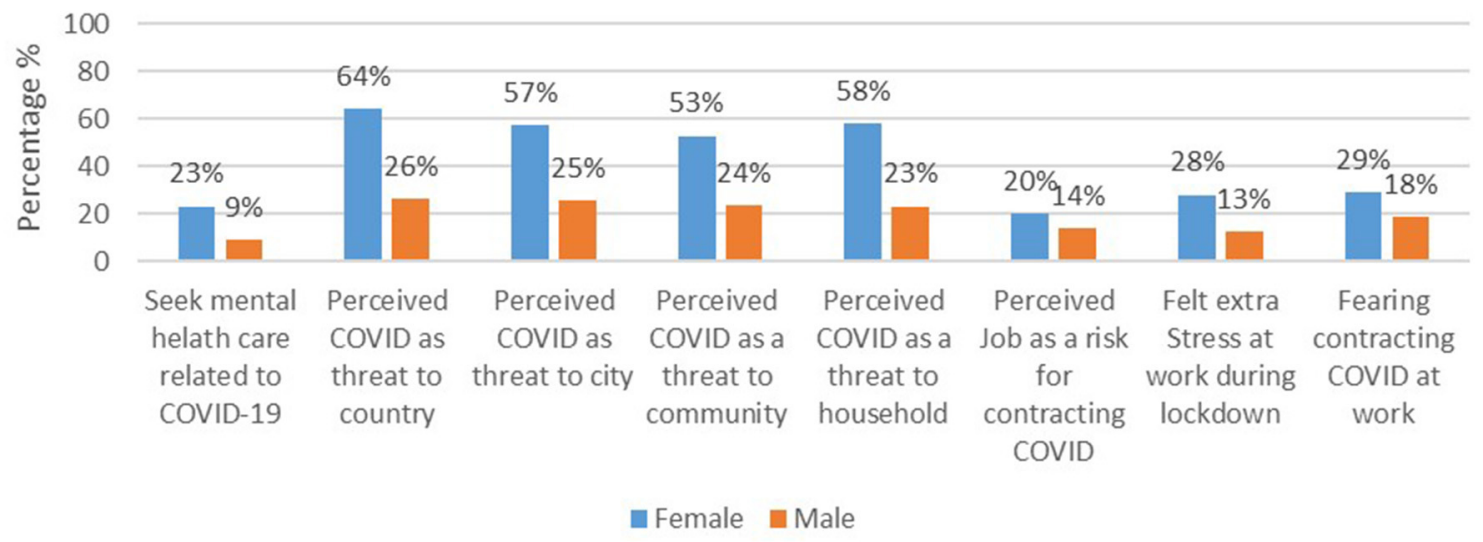

FIGURE 1 | Impact of COVID-19 by gender.

TABLE 2 | Comparison of COVID-19-related impact by gender and age.

\begin{tabular}{|c|c|c|c|c|c|c|}
\hline Variables & \multicolumn{3}{|c|}{ Gender } & \multicolumn{3}{|c|}{ Age } \\
\hline Job putting me at risk for COVID-19 & 24.98 & 8 & $0.002^{* *}$ & 5.93 & 2 & $0.051^{*}$ \\
\hline Extra stress and anxiety at work & 15.40 & 8 & $0.052^{*}$ & & & \\
\hline Fear and worry contracting COVID-19 at work & 26.00 & 8 & $0.001^{\star \star \star}$ & 10.91 & 2 & $0.004^{\star *}$ \\
\hline Perceived threat to community & 40.04 & 20 & $0.005^{\star \star}$ & & & \\
\hline Seek COVID-related mental healthcare & 50.01 & 8 & $0.000^{\star \star \star}$ & & & \\
\hline Previous mental health problem & 259.13 & 8 & $0.000^{\star \star \star}$ & & & \\
\hline Treated for mental health problem & 48.73 & 8 & $0.000^{\star \star \star}$ & & & \\
\hline
\end{tabular}

$X^{2}$, chi-square; $d f$, degrees of freedom.

Levels of significance: ${ }^{\star} p<0.05,{ }^{\star \star} p<0.01,{ }^{\star \star *} p<0.001$.

were the commonest modalities of treatment reported by the participants. Compared with males, females were more likely to report a history of mental illness $X_{(8)}^{2}=40.882, p<0.001$, with depression and anxiety being the more commonly diagnosed disorders. COVID-19 had a differential impact on the mental health of participants with and without mental health diagnoses, $X_{(4)}^{2}=16.596, p=0.002$. Participants with a pre-existing mental health diagnosis were more likely to report extra stress during COVID-19 $(p=0.002)$, consider work stressful $(p<0.001)$ and seek out mental healthcare during the lockdown $(p<0.001)$ (Table 3).

\section{DISCUSSION}

This study confirms a large percentage of participants who completed the study survey experienced adverse psychosocial effects associated with COVID-19 and lockdown in a sample of South Africans. This finding is similar to studies conducted in several countries $(2,12-15)$. Notably, our study found that
TABLE 3 | Relationship between previous diagnosed mental health problem and impact of COVID-19.

\begin{tabular}{lccc}
\hline \multirow{2}{*}{ Variable } & \multicolumn{3}{c}{ Diagnosed mental illness } \\
\cline { 2 - 5 } & $\boldsymbol{X}^{\mathbf{2}}$ & $\boldsymbol{d f}$ & $\boldsymbol{p}$ \\
\hline Job putting me at risk for COVID-19 & 5.596 & 4 & 0.232 \\
Extra stress and anxiety at work & 17.096 & 4 & $0.002^{\star \star}$ \\
Fear and worry contracting COVID-19 at work & 6.926 & 4 & 0.140 \\
Perceived threat to household & 33.480 & 10 & $0.000^{\star \star \star}$ \\
Perceived threat to community & 36.372 & 10 & $0.000^{\star \star \star}$ \\
Seek COVID-related mental healthcare & 22.542 & 10 & $0.000^{\star \star \star}$ \\
\hline
\end{tabular}

$X^{2}$, chi-square; df, degrees of freedom.

Levels of significance: ${ }^{\star *} p<0.01,{ }^{* \star \star} p<0.001$.

more than a third of the participants reported psychological problems as a result of the pandemic. In this study, stress and anxiety; stress about finances; and depressive symptoms were 
significantly higher in women than in men. Similar findings were observed elsewhere (16). Hou et al. (17), in an online recruited study of 3,088 participants from across China, found that females compared to males reported more and severe stress and anxiety during the COVID-19 epidemic. Similar gender differences were observed in the findings by Wang and Tang in their cross-sectional survey of 4,788 men and women from eight provinces across China (18). The researchers found that women comparatively to men reported higher percentages of hopelessness, loneliness, and depression. It is worth noting that while these findings may suggest a gender difference in the mental health vulnerability associated with the pandemic, further research is required to clearly unpack this. Notwithstanding, it is well-established that women are at greater risk for mental health problems than men, especially for mood and anxiety disorders $(19,20)$. In the context of the pandemic, women are at an increased risk of poor mental health outcomes due to vulnerability of intimate partner violence, income insecurity, and the likelihood of loss of livelihood associated with the COVID-19 lockdown (21). Although we did not collect data on the presence of children, it may be the case that some female participants reported higher levels of stress than male participants because the lockdown exacerbated the gender division of family work (i.e., caring of children, chores, etc.) within the households. With the lockdown and the closures of daycares and businesses, it meant women may be doing family work that would have previously been outsourced or taking on more childcare responsibilities, and more homeschooling than men, while outside sources of help such as cleaners, tutors, and support from extended family are not available. The finding suggests that women may be more stressed during the lockdown because they may be over-proportionately burdened by additional responsibilities in the home.

Similar to Nwachukwu et al. our study found that participants in the lower age groups (18-29 years) reported relatively higher percentages of stress, anxiety, and depressive symptomatology (16). However, a significant age effect was only observed for fear and anxiety about contractingCOVID-19 at work and perceiving one's job as a risk for contracting COVID-19. Importantly in contrast to Nwachukwu and colleagues, the participants in our study were spread over a wider younger age 18-39 years, with a younger average (16). Our study, similar to other studies $(16,18,22)$ had a lower representation of the elderly population, and this underrepresentation may be a potential bias in this study that limits generalizability for those older than 55 years of age. Another possible explanation is that persons in the younger age group may have perceived their academic, social, occupational, and economic prospects to be more threatened by COVID-19 compared to older individuals (23).

This study also supports the finding that more women are seeking mental health support as the pandemic pushes up stress, anxiety, and depression (24).

Our study finding is consistent with studies elsewhere that suggest the spread of coronavirus is perceived as a threat and a risk $(25,26)$. Similar to Kanovsky and Halamová (25), our study found that participants who go out to work reported a higher percentage of perceived likelihood of contracting COVID19. Regardless of actual exposure, fear of infection and the risk of transmitting infection between work and family was a major concern for the majority of the participant, a finding that is aligned with previous studies $(27,28)$. Interestingly, in a study, Niño et al. (29) found that race and ethnicity, gender, and age play a significant role in the threat and fear perceptions of COVID19. Remaining to be unpacked in future studies is the underlying factors that can explain differences in perception of risk during an infectious disease outbreak.

Consistent with previous studies, our finding confirms the potential impact of the COVID-19 pandemic on participants with a self-reported history of mental health problems $(28,30)$.

In light of the above findings, it is imperative for the government to prioritize the mental health needs of its people by providing the necessary psychosocial health support. The prolonged lockdown situation may continue to contribute to increasing levels of distress, fear of losing jobs, and stress associated with restricted movement outside of the home and increasing responsibility within the home context. Particular attention should be given to multiple role handling that is particularly relevant for women who continue to engage in more child care, homeschooling of children, and domestic responsibilities, while also performing full-time jobs from home. Psychologists and other mental health practitioners can play an important role in meeting the mental health needs of the general population during the ongoing pandemic by assisting governments in tailoring psychosocial interventions. Online or smartphone-based psychological interventions have been promoted as an effective solution in this pressing time of global emergency. We, therefore, recommend the active and ongoing participation of government, mental health policymakers, and mental health professionals as a joint effort during this critical time to ensure the psychosocial well-being of all people (31). Employers can also directly support employees, especially providing women with flexible working schedules, pay women equal wages and spare them the stress, and make mental healthcare accessible through employer-based healthcare plans.

\section{Limitations of the Study}

Our study is not without limitations. First, the issue of generalizability is highlighted in the small sample size that is not representative of the South African population. Due to the nationwide lockdown and movement restriction, we had to rely solely on collecting the data via an online survey, which might not represent the population as uniformly as one would like in such studies. This may have introduced several issues such as the inability to reach the wider and perhaps the most marginalized population (i.e., the poor, elderly, disabled, and people with limited or no education). Also, those individuals who are not computer literate, who do not have access to the internet, smartphones, or relevant digital resources were also limited from participating. Second, the data collected for this study is limited only to the first wave of infection in South Africa. Furthermore, data were self-reported, and thus the potential of reporting bias may have been introduced. In addition, the study reported on a limited selection of symptoms. Future studies can address this by incorporating a broad range of psychosocial consequences of COVID-19. Third, we did not ask if the participants or 
their families had exposure to COVID-19. Finally, this study was based on cross-sectional data, and the associations cannot indicate causality. Despite these limitations, the findings of this study contribute to our understanding of the psychosocial consequences of COVID-19.

\section{CONCLUSION}

A large percentage of the participants had psychosocial problems associated with the pandemic lockdown. Women as opposed to men and patients with a prior mental health diagnosis are especially vulnerable to the adverse outcomes of COVID-19. In conclusion, future research should explore the psychosocial health changes of a cohort over time as the pandemic evolves in South Africa.

\section{DATA AVAILABILITY STATEMENT}

The raw data supporting the conclusions of this article will be made available by the authors, without undue reservation.

\section{REFERENCES}

1. ICN COVID-19 Update: New guidance on mental health and psychosocial support will help to alleviate effects of stress on hard-pressed staff [Internet]. ICN - International Council of Nurses. Available online at: https://www. icn.ch/news/icn-covid-19-update-new-guidance-mental-health-andpsychosocial-support-will-help-alleviate (accessed Mar 29, 2020).

2. Zhu Z, Xu S, Wang H, Liu Z, Wu J, Li G, et al. COVID-19 in Wuhan: immediate psychological impact on 5062 health workers. medRxiv. (2020) 2020:2020.02.20.20025338. doi: 10.1101/2020.02.20.20025338

3. Durrheim DN, Gostin LO, Moodley K. When does a major outbreak become a Public Health Emergency of International concern? Lancet Infect Dis. (2020) 20:887-9. doi: 10.1016/S1473-3099(20)30401-1

4. Cucinotta D, Vanelli M. WHO declares COVID-19 a pandemic. Acta Biomed. (2020) 91:157-60. doi: 10.23750/abm.v91i1.9397

5. Geffen BN. How Many People Could Die of Covid-19 in South Africa? GroundUp News (2020). Available online at: https://www.groundup.org.za/ article/how-many-people-coulddie-covid-19-south-africa/ (accessed March $30,2020)$.

6. Lambert H, Gupte J, Fletcher H, Hammond L, Lowe N, Pelling M, et al. COVID-19 as a global challenge: towards an inclusive and sustainable future. Lancet Planet Health. (2020) 4:e312-4. doi: 10.1016/S2542-5196(20) 30168-6

7. Denckla CA, Gelaye B, Orlinsky L, Koenen KC. REACH for mental health in the COVID19 pandemic: an urgent call for public health action. Eur J Psychotraumatol. (2020) 11:1762995. doi: 10.1080/20008198.2020.17 62995

8. O'Leary A, Jalloh MF, Neria Y. Fear and Culture: Contextualising Mental Health Impact of the 2014-2016 Ebola Epidemic in West Africa. BMJ Glob Health (2018) 3. Available online at: https://www.ncbi.nlm.nih.gov/pmc/ articles/PMC6035506/ (accessed March 30, 2020).

9. Chapman B, Swainston J, Grunfeld EA, Derakshan N. COVID19 outbreak effects on job security and emotional functioning amongst women living with breast cancer. Front Psychol. (2020) 11:582014. doi: 10.3389/fpsyg.2020.582014

10. Zhang SX, Wang Y, Rauch A, Wei F. Unprecedented disruption of lives and work: health, distress and life satisfaction of working adults in China one month into the COVID-19 outbreak. Psychiatry Res. (2020) 288:112958. doi: 10.1016/j.psychres.2020.112958

\section{ETHICS STATEMENT}

The studies involving human participants were reviewed and approved by Sefako Makgatho University Research Ethics Committee (SMUREC/M/73/2020: IR). The patients/participants provided their written informed consent to participate in this study.

\section{AUTHOR CONTRIBUTIONS}

$\mathrm{AL}$ and MM contributed to conception and design of the study and wrote sections of manuscripts. AL performed statistical analysis and wrote the first draft of the manuscripts. Both authors contributed to manuscript revision, read, and approved the submitted version.

\section{ACKNOWLEDGMENTS}

The researchers acknowledge the participants who took part in this study.

11. Stewart R, El-Harakeh A, Cherian SA. Evidence synthesis communities in lowincome and middle-income countries and the COVID-19 response. Lancet. (2020) 396:1539-41. doi: 10.1016/S0140-6736(20)32141-3

12. Cao W, Fang Z, Hou G, Han M, Xu X, Dong J, et al. The psychological impact of the COVID-19 epidemic on college students in China. Psychiatry Res. (2020) 287:112934. doi: 10.1016/j.psychres.2020.112934

13. Dubey S, Biswas P, Ghosh R, Chatterjee S, Dubey MJ, Chatterjee S, et al. Psychosocial impact of COVID-19. Diabetes Metab Syndr. (2020) 14(5):77988. doi: 10.1016/j.dsx.2020.05.035

14. Odriozola-González P, Planchuelo-Gómez Á, Irurtia MJ, de Luis-García R. Psychological effects of the COVID-19 outbreak and lockdown among students and workers of a Spanish university. Psychiatry Res. (2020) 290:113108. doi: 10.1016/j.psychres.2020.113108

15. Raza SH, Haq W, Sajjad M. COVID-19: a psychosocial perspective. Front Psychol. (2020) 11:554624. doi: 10.3389/fpsyg.2020.554624

16. Nwachukwu I, Nkire N, Shalaby R, Hrabok M, Vuong W, Gusnowski A, et al. COVID-19 pandemic: age-related differences in measures of stress, anxiety and depression in Canada. Int J Environ Res Public Health. (2020) 17:6366. doi: 10.3390/ijerph17176366

17. Hou F, Bi F, Jiao R, Luo D, Song K. Gender differences of depression and anxiety among social media users during the COVID-19 outbreak in China:a cross-sectional study. BMC Public Health. (2020) 20:1648. doi: 10.1186/s12889-020-09738-7

18. Wang G-Y, Tang S-F. Perceived psychosocial health and its sociodemographic correlates in times of the COVID-19 pandemic: a community-based online study in China. Infect Dis Poverty. (2020) 9:148. doi: 10.1186/s40249-020-00770-8

19. Maiti T, Rai B. Women mental health during COVID 19 and lock down: a brief narrative and introspection. Clin Psychiatr. (2020) 6:71. doi: 10.36648/2471-9854.6.3.71

20. Seedat S, Scott KM, Angermeyer MC, Berglund P, Bromet EJ, Brugha TS, et al. Cross-national associations between gender and mental disorders in the World Health Organization World Mental Health Surveys. Arch Gen Psychiatry. (2009) 66:785-95. doi: 10.1001/archgenpsychiatry.2009.36

21. Evans ML, Lindauer M, Farrell ME. A pandemic within a pandemic intimate partner violence during Covid-19. N Engl J Med. (2020) 383:23024. doi: 10.1056/NEJMp2024046

22. González-Sanguino C, Ausín B, Castellanos MÁ, Saiz J, López-Gómez A, Ugidos C, et al. Mental health consequences during the initial stage of the 2020 
coronavirus pandemic (COVID-19) in Spain. Brain Behav Immun. (2020) 87:172-6. doi: 10.1016/j.bbi.2020.05.040

23. Wang Y, Di Y, Ye J, Wei W. Study on the public psychological states and its related factors during the outbreak of coronavirus disease 2019 (COVID-19) in some regions of China. Psychol Health Med. (2021) 26:1322. doi: 10.1080/13548506.2020.1746817

24. Cunningham M. "Absolutely flooded": record numbers of women seek mental health help. The Age. (2020). Available online at: https://www.theage. com.au/national/victoria/absolutely-flooded-record-numbers- of-womenseek-mental-health-help-20200921-p55xmx.html (accessed Jan 23, 2021).

25. Kanovsky M, Halamová J. Perceived threat of the coronavirus and the role of trust in safeguards: a case study in Slovakia. Front Psychol. (2020) 11:554160. doi: 10.3389/fpsyg.2020.554160

26. Khosravi M. Perceived risk of COVID-19 pandemic: the role of public worry and trust. Electron J Gen Med. (2020) 17:em203. doi: 10.29333/ej $\mathrm{gm} / 7856$

27. Nabe-Nielsen K, Nilsson CJ, Juul-Madsen M, Bredal C, Hansen LOP, Hansen ÅM. COVID-19 risk management at the workplace, fear of infection and fear of transmission of infection among frontline employees. Occup Environ Med. (2020). 1-7. doi: 10.1136/oemed-2020-106831

28. Newby JM, O'Moore K, Tang S, Christensen H, Faasse K. Acute mental health responses during the COVID-19 pandemic in Australia. PLOS ONE. (2020) 15:e0236562. doi: 10.1371/journal.pone.0236562
29. Niño M, Harris C, Drawve G, Fitzpatrick KM. Race and ethnicity, gender, and age on perceived threats and fear of COVID-19: evidence from two national data sources. SSM Popul Health. (2021) 13:100717. doi: 10.1016/j.ssmph.2020.100717

30. Holmes EA, O'Connor RC, Perry VH, Tracey I, Wessely S, Arseneault L, et al. Multidisciplinary research priorities for the COVID-19 pandemic: a call for action for mental health science. Lancet Psychiatry. (2020) 7:54760. doi: 10.1016/S2215-0366(20)30168-1

31. Moreno C, Wykes T, Galderisi S, Nordentoft M, Crossley N, Jones $\mathrm{N}$, et al. How mental health care should change as a consequence of the COVID-19 pandemic. Lancet Psychiatry. (2020) 7:813-24. doi: 10.1016/S2215-0366(20)30307-2

Conflict of Interest: The authors declare that the research was conducted in the absence of any commercial or financial relationships that could be construed as a potential conflict of interest.

Copyright (c) 2021 Lentoor and Maepa. This is an open-access article distributed under the terms of the Creative Commons Attribution License (CC BY). The use, distribution or reproduction in other forums is permitted, provided the original author(s) and the copyright owner(s) are credited and that the original publication in this journal is cited, in accordance with accepted academic practice. No use, distribution or reproduction is permitted which does not comply with these terms. 